\title{
Design and Manufacturing of Vermicompost Cleaning Machine
}

\author{
Prof. P. D. Kabudake, Ghorpade Pradumnya, Jagdale Aditi, Gholap Sanket, Kambale Madhuri \\ Department of Mechanical engineering. \\ Pravara Rural Engineering College. \\ Loni, India.
}

\begin{abstract}
Vermicomposting is an innovative technology trend that has attracted many young entrepreneurs. It makes use of certain kind of earthworms to convert organic solid waste into vermicompost. Vermicomposting pit consist of worm casting, undigested organic matter and live worms altogether. The manual process of separation of vermicast and live worms is a very time consuming and cumbersome process. Therefore, in this paper design schemes for manufacturing of vermicompost cleaning machine has been introduced. The end result depict that the vermicompost cleaning machine requires a lot less time and labor as compared to manual cleaning.
\end{abstract}

Keywords-Vermicomposting; worm castings; earthworms; seive;

\section{INTRODUCTION}

Vermicomposting is a recent technology trend that has attracted many young entrepreneurs. It is a technique in which organic matter is converted to manure. In contrast to composting where huge pits of organic waste is decomposed in presence of air to create manure which is basically decayed organic matter, vermicomposting is a technique in which earthworms are used to convert the organic matter into manure[1]. This process is usually cold as compared to composting and requires around 25-30 degree Celsius temperature with around $50 \%$ to $60 \%$ moisture and neutral $\mathrm{PH}$. Usually red wigglers (Eisenia foetida), White worms and many other kind of earthworms are used. These worms feed on the organic matter like kitchen waste, agro waste etc. [2]. The worms excrete vermicast which is an odorless black moist substance. This vermicast is saturated in nutrient content and is an excellent fertilizer which is water soluble in nature. This process is usually carried out under shade so as to not cause damage to worms due to sunlight. The pit may expand any dimensions in length and breadth but the maximum depth is not more than two feet. Beddings are created using finely chopped organic matter. The pits need watering on regular basis and worms are introduced in the pits only after the pit temperature is lowered to an extent where the worms can thrive. Watering is stopped well before the harvesting and the vermicompost is separated from the worms using sieves. This process is manual and consumes a lot of time and labor. To elucidate this problem may researchers have introduced various schemes. A new machine for rapid separation of earthworms and substrate has been introduced in [3] it uses a light source to drive away the worms into a separate compartment and then use a sets of some motor driven sieves to separate the substrates. Reference [4] has introduced use of rotary trammel screen separator and achieved up to $90 \%$ efficient separation at about $60 \%$ moisture content. In [5] a separator is designed to separate raw compost from vermicompost using rotating cylinder driven by electric motor. Also [6] has introduced a two stage separator the particles with size less than $6 \mathrm{~mm}$ are separated using a rolling screen and the earthworms are separated from the vermicompost using special conical separator with a survival rate of 96 percent. In [7] effect of screen mesh size on performance of thee vermicomposting bed has been discussed. Reference [8] has shown effects of electric currents to repel earthworms. The study is done by recording effect of electric current repelling worms from a sample as a function of voltage across it. Reference [9] shows study on design and fabrication of sieve machine. In [10] New machine which is based on combing action is used to separate worms from the compost which had well moisture levels in it. Also the problem of blinding worms is addressed. This paper aims at creating a low cost separator for small scale applications, therefore design is based on improving design of rotary separator to cause less harm to worms.

The rest of the paper is arranged as follows. Section 2 depicts component selection and design. Section 3 shows Working of the system. Results are discussed in section 4. And section 5 concludes the paper.

\section{COMPONENT SELECTION AND DESIGN}

A. List of Components

TABLE I: List of components

\begin{tabular}{|l|l|c|c|}
\hline \multirow{2}{*}{ Sr.no } & \multicolumn{3}{|c|}{ Table Column Head } \\
\cline { 2 - 4 } & \multicolumn{1}{|c|}{ Component } & specifications & quantity \\
\hline 1 & Motor & $\begin{array}{c}\text { Single phase } \\
\text { 230V AC 1.5HP }\end{array}$ & 1 \\
\hline 2 & Gearbox & $\begin{array}{c}36: 1 \text { Reduction } \\
\text { ratio }\end{array}$ & 1 \\
\hline 3 & Pulley & Diameter=200mm & 4 \\
\hline 4 & Shaft & Diameter=30mm & 1 \\
\hline 5 & Hopper & $\begin{array}{c}\text { 20kg weight } \\
\text { capacity }\end{array}$ & 1 \\
\hline 6 & $\begin{array}{l}\text { Cylindrical } \\
\text { Seive }\end{array}$ & $\begin{array}{c}\text { Length }=2133 \mathrm{~mm} \\
\text { Diameter=510mm }\end{array}$ & 1 \\
\hline 7 & Collector & $\begin{array}{c}\text { Weight capacity }= \\
10 \mathrm{~kg}\end{array}$ & 1 \\
\hline 8 & Belt & v groove type & 2 \\
\hline
\end{tabular}

\section{B. Design Details}

In this section design details of motor, shaft, frame, gearbox, sieve and bearings are discussed. The design discussed is aimed at creating a cost effective device for vermicompost separation to be used at cattle farms, agricultural purposes domestic purposes and medium scale industries. 


\section{a) Motor selection}

The motor used for this application is a $230 \mathrm{~V}$ single phase AC motor.

The total weight acting on the motor is $=294.3 \mathrm{~N}$

Required torque $=7.173 \mathrm{Nm}$

Power required is given by,

$\mathrm{P}=(2 * \pi * \mathrm{~N} * \mathrm{~T}) / 60$

$\mathrm{P}=(2 * \pi * 1440 * 7.173) / 60$

$\mathrm{P}=1.5 \mathrm{HP}$

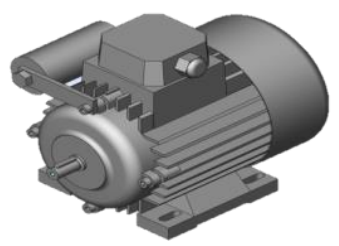

Fig. 1. AC motor.

b) Shaft and cylindrical seive design

The shaft used in this application is used to support the weight of the cylindrical sieve and the compost in it which is to be separated along with accessories like belt and pulley. Assuming the total torque at the shaft to be $300 \mathrm{Nm}$

Shear stress of shaft material $(\mathrm{C} 40)=500 \mathrm{mpa}$

According to torque stress relationship,

$\mathrm{T}=\sigma \times\left(\frac{\pi}{16}\right) \times d^{3}$

$\therefore 300=500 \times\left(\frac{\pi}{16}\right) \times d^{3}$

$\therefore \mathrm{d}=14.51 \mathrm{~mm}$

as per standerd size $\mathrm{d}=30 \mathrm{~mm}$.

The cylindrical seive used is of DOT 4 rating to extract only useful compost.

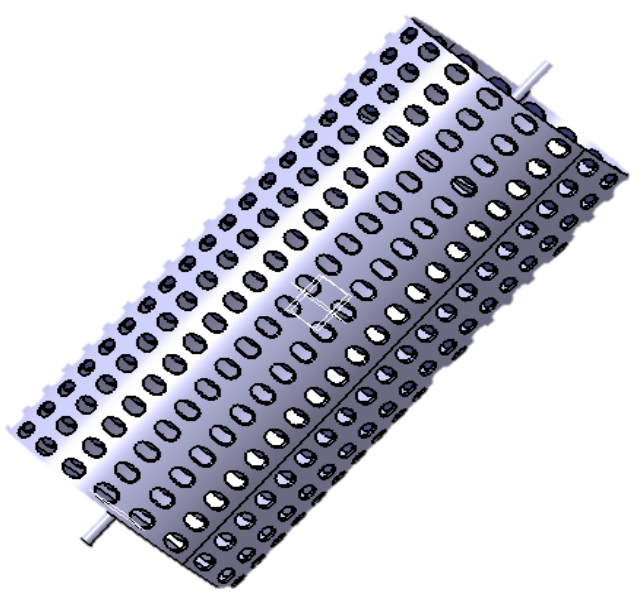

Fig. 2. Cylindrical sieve and shaft.

c) Frame design

The total weight acting on the frame is assumed to be around $400 \mathrm{~N}$

$\therefore$ converting UDL in Point load we have,

$\therefore 400 \times 2135=854000 \mathrm{~N}$

Stress on Frame $=\frac{F}{A}=\frac{854000}{2836.34}=301.09 \mathrm{~N} / \mathrm{mm}^{2}$

For Safe Design,
Required stress $=$ Estimated stress $\times$ FOS

$\therefore 301.09 \times 1.2=361.308 \mathrm{~N} / \mathrm{mm}^{2}$

Therefore, the material selected is $\mathrm{C}_{40}$ which has characteristics required by the design.

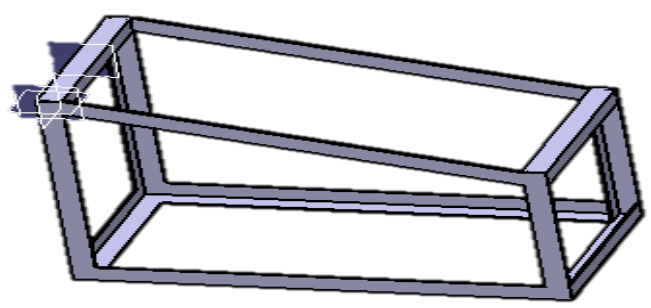

Fig. 3. Frame structure.

d) Bearing selection

For this application we select pedestal bearing,

Radial force on pulley $=1480 \mathrm{~N}$

Diameter of shaft $=30 \mathrm{~mm}$

Equivalent dynamic load

$\mathrm{P}_{\mathrm{e}}=\mathrm{Fr} \times \mathrm{Ka}$

$\therefore 69.64 \times 1.25=87.05$

Rating life of bearig in million revolutions

$\mathrm{L}_{10}=720 \mathrm{MR}$

Dynamic load carrying capacity

$\mathrm{L}_{10}=(\mathrm{C} / \mathrm{Pe})^{3}$

$\mathrm{C}=780 \mathrm{~N}$

From manufacturing catalogue we select bearing no- 61806

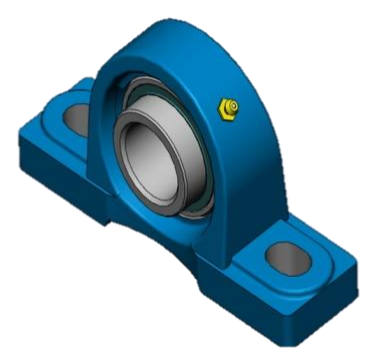

Fig. 4. Pedestal bearing.

e) Gearbox, Pulley, Belts and Hopper selection

The gearbox is used to provide a reduction from AC motor to shaft. The shaft is required to be rotated at $40 \mathrm{RPM}$ so as not to harm the worms. Therefore the required reduction calculated comes out to be $36: 1$. Such high reduction ratio can be obtained using worm type gear box only.

To keep the ratios constant V Pulleys of the same size are used along with belts. The hoppers are selected on basis of its weight capacity to accommodate around $10 \mathrm{~kg}$ of compost at once. 


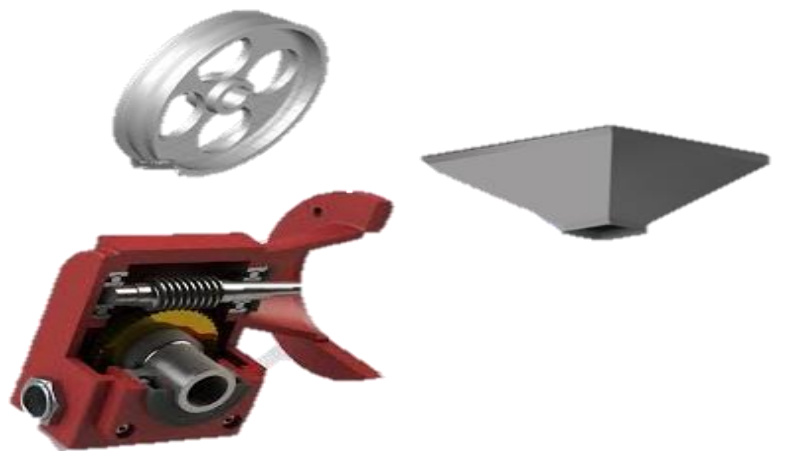

Fig. 5. Worm gearbox, pulleys, and hopper.

III. WORKING OF THE SYSTEM

Vermicompost cleaning machine is very easy to construct and can be operated easily. It is very economic among this kind of machines and is targeted for users which work on small scale or cattle farm level. This machine is both simple in construction and working and can be operated easily by virtually anybody. The figure 5 below shows the developed CAD model of the proposed system.

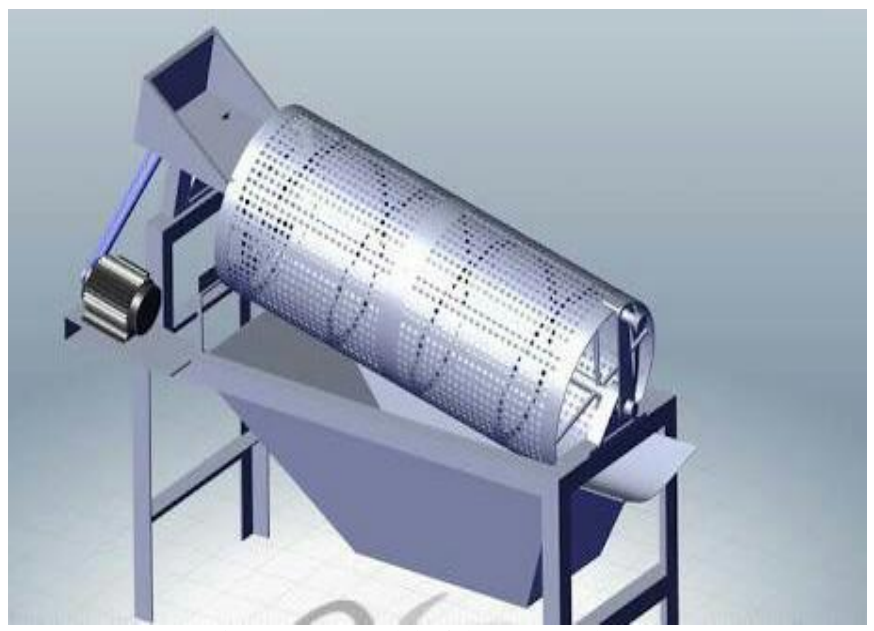

Fig. 6. CAD model of the proposed system.

This system is fabricated with the help of parts like cylindrical sieve, shaft, hopper, frame, bearings, motor, and pulleys. This vermicompost separation system works on the basis of simple rotary mechanism. An electric motor is mounted on the frame and connected to the shaft of cylindrical sieve through gearbox and pulley system. After turning on the AC motor the sieve starts rotating at $40 \mathrm{RPM}$. The prepared compost is then fed into the hopper mounted at some height above the frame. The compost fed into the hopper keeps falling into the rotating sieve due to gravity at a constant rate. As the sieve is rotating the sieving action will take place. Due to the inclination of the sieve with respect to horizontal and gravitational force acting on the compost particles, the useful compost is sieved out and gets settled in the collector while the un compost matter along with live worms are collected in a separate collector. The worms then can be transferred back to the pit for vermicomposting and the final product which is often called as "Black Gold" can be packed.

\section{RESULTS AND DISCUSSION}

The proposed system can be easily fabricated at low cost for small scale industries and cattle farms. The manual effort earlier required now reduced drastically. The operating time is also reduced increasing efficiency. Since, the system is quite small in small in size it occupies very less floor area rendering more space for creating vermicompost pit. Also the net weight of the system is quite less and can be transported easily. The limited number of parts and very less stressed members present in the system reduce the chances of breakdown making the system almost maintenance free. With reduction of process time and labor individual owner can also save capital. The cost estimation of the system is given in table 2 below.

TABLE II: Cost estimation.

\begin{tabular}{|l|l|l|l|}
\hline Sr. No. & Component & Qty. & Cost (INR) \\
\hline 1 & Motor & 1 & 4500 \\
\hline 2 & $\begin{array}{l}\text { Worm Gear } \\
\text { Box }\end{array}$ & 1 & 3000 \\
\hline 3 & Pulley & 4 & 1000 \\
\hline 4 & Belt & 2 & 400 \\
\hline 5 & Hopper & 1 & 800 \\
\hline 6 & Frame & 1 & 400 \\
\hline 7 & seive & 1 & 1065 \\
\hline 8 & Bearing & 2 & 700 \\
\hline $\begin{array}{l}\text { TOTAL } \\
\text { COST }\end{array}$ & & 1 & 300 \\
\hline & & & 18465 \\
\hline & & & \\
\hline & & & \\
\hline & & & \\
\hline & & & \\
\hline & & & \\
\hline & & & \\
\hline
\end{tabular}

Figure 7 below shows the system in its initial stages of development operated manually to find out best outcome by iterating various speeds and inclination of cylindrical sieve so as to not cause discomfort and trauma to the worms.

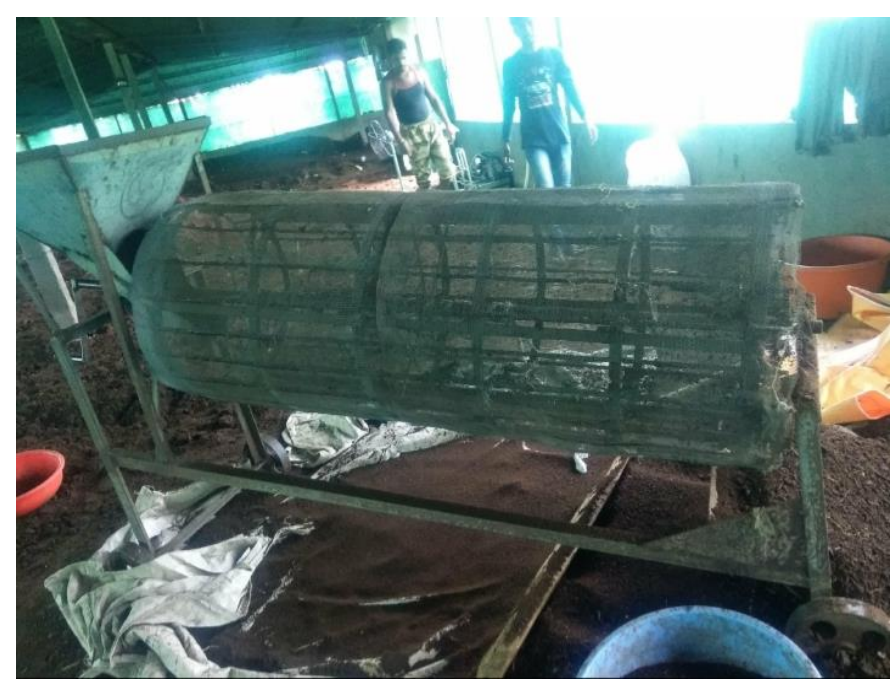

Fig. 7. Initial development prototype of the system. 


\section{CONCLUSION}

In this paper design schemes for development of a low cost vermicompost cleaning machine have been proposed for use in small scale and domestic cattle farms. The system designed is quite robust and is almost maintenance free. Due to sieving operation worms and compost get separated easily and worms get reused. Also the use of DOT4 sieve causes less damage to worms. As we use worm gearbox its speed is in control and we can separate worms without harming them. Also, a collector provided at the bottom reduces wastage of compost and get collected efficiently and easily.

\section{ACKNOWLEDGMENT}

We wish to acknowledge the help provided by our project guide Prof. P. D. Kabudake and Mr. Borade and our supervisors who helped us in completing and finalizing our work.

\section{REFERENCES}

[1] Dominguez, J., C. A. Edwards, and S. Subler. "A comparison of vermicomposting and composting." Biocycle 38 (1997): 57-59.

[2] Garg, Payal, Asha Gupta, and Santosh Satya. "Vermicomposting of different types of waste using Eisenia foetida: A comparative study." Bioresource technology 97, no. 3 (2006): 391-395.
[3] Tauseef, S.M. \& Abbasi, Tasneem \& Banupriya, G. \& Banupriya, D. \& Abbasi, S. A.. (2014). A new machine for clean and rapid separation of vermicast, earthworms, and undigested substrate in vermicomposting systems. J. Environ. Sci. Eng.. 56. 495-498.

[4] Manyuchi, Musaida, and Anthony Phiri. "Effective Separation of Vermicasts fromEarthworms Using a Cylindrical Rotary Trommel Separator." (2013).

[5] Hoque, M. A., M. A. Wohab, M. A. Hossain, M. N. Amin, and M. S. Hassan. "DESIGN AND DEVELOPMENT OF A COMPOST SEPARATOR."

[6] Lin, Jiacong, Shuai Zhao, Qiaoxia Yuan, Qinjing Liao, Mingyang Liu, and Yunfan Wang. "Rapidly Separating Earthworm from Vermicompost Using Two-Step Technology." Waste and Biomass Valorization (2020): $1-15$.

[7] Montepio, Roger, and Ryan Abenoja. "Effect of Operating Conditions and Screen Mesh Size on the Performance of Vermicomposting Bed with Automated Harvester and Watering System." Southeastern Philippines Journal of Research and Development 24, no. 2 (2019): 79-105.

[8] Chaoui, Hala, and Harold M. Keener. "Separating earthworms from organic media using an electric field." Biosystems engineering 100, no. 3 (2008): 409-421.

[9] Mohjee, Mohd Effi. "Design and Fabricate Sieve Machine." (2008).

[10] Price, J. S., and V. R. Phillips. "An improved mechanical separator for removing live worms from worm-worked organic wastes." Biological wastes 33, no. 1 (1990): 25-37. 